\begin{tabular}{|cc|}
\hline WOOD & COMBUSTION \\
STOVE & BURNER \\
SMOKE & PHENOLS \\
BENZENE & PAH \\
ANALYSIS & GC - MS \\
\hline
\end{tabular}

Open access revised manuscript version of Biomass and bioenergy 24 (2003) 51-57

Link to publisher: doi:10.1016/50961-9534(02)00083-1

\title{
Specific chimney emissions and biofuel characteristics of softwood pellets for residential heating in Sweden
}

\author{
Maria Olsson, Jennica Kjällstrand and Göran Petersson
}

Related articles on burning of wood pellets emphasize phenolic compounds and volatile hydrocarbons 


\title{
Specific chimney emissions and biofuel characteristics of softwood pellets for residential heating in Sweden
}

\author{
Maria Olsson, Jennica Kjällstrand, Göran Petersson* \\ Department of Chemical Environmental Science, Chalmers University of Technology, \\ SE-41296 Göteborg, Sweden
}

\begin{abstract}
Softwood pellets are mainly produced from sawdust and to some extent from wood shavings. The moisture content is typically less than half of that in firewood. The present annual residential use in Sweden for pellet burners in boilers and for pellet stoves amounts to more than 100000 tonnes and is increasing rapidly. The total annual production capacity at the more than 20 units exceeds one million tonnes, and permits continued rapid replacement of firewood and petroleum oil for residential heating.

With the purpose of characterising emissions to air, chimney smoke was sampled, and specific compounds were assessed by gas chromatography and mass spectrometry. Benzene was the predominant aromatic compound in emissions from pellet burners. The smoke from stoves contained methoxyphenols with antioxidant properties and lower proportions of aromatic hydrocarbons. Observed differences in emissions from specific burning appliances are of interest with regard to both health hazards and regulation of emissions.

Consideration of ecological aspects and pollution hazards indicates that wood pellets should be used primarily for residential heating, whereas controlled large-scale combustion is preferable for most other types of biomass waste.
\end{abstract}

Keywords: Wood pellets; Stoves; Burners; Benzene; PAH; Phenols; Biomass waste 


\section{Introduction}

Wood pellets have been introduced in the course of the last twenty years as a convenient and economically attractive biofuel in forested countries like Sweden [1]. For residential heating, conventionally measured average emissions are lower for pellets than for firewood and for other coarse fuels such as lignite briquettes [2]. The emissions of dioxins (PCDF/PCDD) and chlorophenols are much lower from wood pellets than from fuel pellets based on crops or waste, which contain more chlorine [3]. The storage properties of wood pellets with their low content of moisture and nutrients are favourable [4]. Pellets can also be conveniently transported [1].

Pellets produced from sawdust and wood shavings are very different from firewood with regard to both moisture content and physical structure. It is therefore of interest to determine chimney emissions of specific organic compounds from pellet burning. Comparisons can then be made with primary thermal degradation products released from wood pellets [5], from firewood [6] and from forest biomass [7]. Comparisons can also be made with emitted volatile hydrocarbons from firewood [8].

This article gives data from an inventory of the production and use of wood pellets in Sweden. Emissions of aromatic hydrocarbons, phenols and other aromatic compounds from pellet burning in residential stoves and boilers are reported. The analytical key to the wide range of assessed compounds was the adsorption on Tenax cartridges in combination with thermal desorption and GC-MS with proper chromatographic performance [6]. A wider perspective addressed is an environmentally sustainable use of wood pellets in relation to other biofuels. 


\section{Materials and methods}

\subsection{Pellet-burning appliances and field measurements}

The burners investigated were Sahlins EcoTec A3, 25 kW (burner I), Sahlins EcoTec B1, 30-50 kW (burner IA), PellX P20, $10 \mathrm{~kW}$ or $20 \mathrm{~kW}$ (burner II) and Janfire Flex-a, $23 \mathrm{~kW}$ (burner III). The stoves investigated were Calimax Sandor, $7 \mathrm{~kW}$ (stove I) and Austroflamm Integra, $11 \mathrm{~kW}$ (stove II). Swedish commercial $6 \mathrm{~mm}$ or $8 \mathrm{~mm}$ softwood pellets were burnt.

Smoke temperatures were in the range $40-100^{\circ} \mathrm{C}$ and smoke fluxes in the range $50-250$ $\mathrm{m}^{3} / \mathrm{h}$. Real-time measurements of $\mathrm{CO}, \mathrm{CO}_{2}$ and $\mathrm{O}_{2}$ concentrations were made using a Testo 300M gas analyser (Nordtech Instrument $A B$ ).

\subsection{Sampling and laboratory determinations}

Tedlar bag samples were used for laboratory control of $\mathrm{CO}, \mathrm{CO}_{2}$ and $\mathrm{CH}_{4}$ concentrations by gas chromatography. The solid stationary phases were the porous polymer HayeSep Q for $\mathrm{CO}_{2}$ (thermal conductivity detector) and the molecular sieve $13 \mathrm{X}$ for $\mathrm{CO}$ (thermal conductivity detector) and $\mathrm{CH}_{4}$ (flame ionisation detector).

The Tedlar bag samples were also used for gas chromatographic assessment of methane and benzene by gas injection, separation on an aluminium oxide column and flame ionisation detection. The performance of this column for volatile hydrocarbons from wood burning has been previously reported [8].

Samples of semi-volatile aromatic compounds, including methoxyphenols, were taken on Tenax adsorbent cartridges in the chimney and subsequently analysed by GC-MS in the laboratory. The desorption temperature was $220^{\circ} \mathrm{C}$ and the stationary phase of the capillary column was the cyanopropylphenylsilicone Rtx 1701. The oven temperature was increased by $10^{\circ} \mathrm{C} \min ^{-1}$ from $-50^{\circ} \mathrm{C}$ to $50^{\circ} \mathrm{C}$ and by $5^{\circ} \mathrm{C} \min ^{-1}$ from $50^{\circ} \mathrm{C}$ to $250^{\circ} \mathrm{C}$. The ion trap mass 
spectrometer was Varian Saturn 2000 with electron impact ionisation. Further analytical data were given in a previous study of chimney smoke from firewood burning [6].

\section{Results and discussion}

\subsection{Wood pellets in Sweden}

The map in Fig. 1 illustrates the current Swedish production of wood pellets. More than 20 units produce pellets in quantities varying from 1000 to 100000 tonnes annually. Telephone interviews were conducted, in order to collect information on raw materials, production methods, produced volumes, customers and market.

The major raw material $(60-70 \%)$ is sawdust, mainly from timber sawmills. Several producers use wood shavings, exclusively or partly, which typically have a lower moisture content than sawdust. Sawdust is dried, and pellets with a standardised moisture content of less than $10 \%$ are produced from both materials. Firewood contains at least twice as much water.

In Sweden, softwood pellets from Norway spruce and Scots pine predominate. Chips from logging residues and bark from pulp mills and sawmills are normally used directly as biofuels in heating plants and are only rarely converted to pellets.

Pellets are produced by pressure extrusion, which heats the raw material to about $100{ }^{\circ} \mathrm{C}$. Cylindrical pieces, a few $\mathrm{cm}$ in length and normally 6 or $8 \mathrm{~mm}$ in diameter, are formed. Adhesives are normally not used for wood pellets, but $0.5-1 \%$ of potato starch or lignosulphonates is added by some producers to retain the integrity of the pellets. Lignosulphonates increase sulphur emissions to air and will probably be phased out.

The production volumes given in Fig. 1 can be compared with those reported up until 1996 in a similar inventory [1]. The production capacity has increased very rapidly from only 10000 tonnes in 1990 to 1000000 tonnes in the year 2000 . The major portion (80\%) of the 


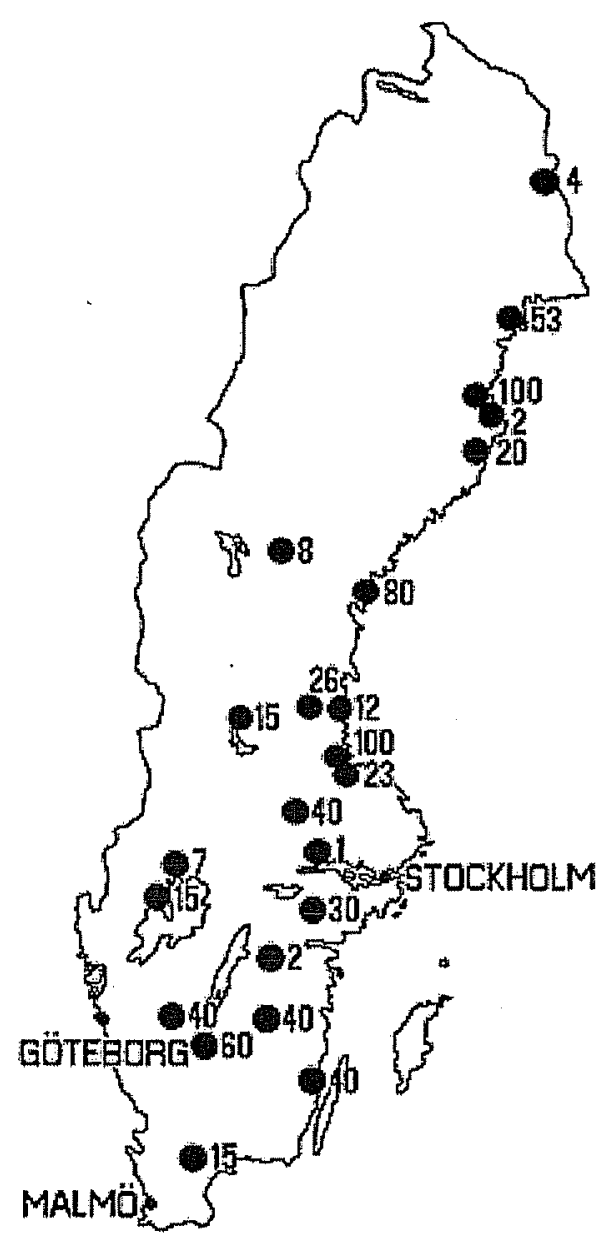

Fig. 1 Production of wood pellets in Sweden during the year 2000 (in thousands of tonnes) 
produced pellets is still burnt in large heating plants. The use of pellets for residential heating in Sweden now amounts to more than 100000 tonnes and increases steadily by typically $30 \%$ annually. About 10000 pellet burners have been installed in residential boilers during the past two years. With their automatic feed they offer a convenient, as well as economical, alternative to oil burners and firewood boilers. The residential use of pellets is about one order of magnitude larger for burners than for stoves in Sweden.

\subsection{Emissions from pellet burners in residential boilers}

Measurements were focused on two private residential boilers, with different burners (I and II). General emission data are given in Table 1, permitting comparisons between conventionally recorded gases and the specific assessed organic compounds.

The emissions of the key compounds carbon monoxide, methane and benzene were much larger from burner I than from burner II. This may be due to an unfortunate combination of burner I and the boiler and illustrates the importance of realistic chimney smoke studies. Burner II gives rise to significant emissions at low burner effect but extremely low emissions at full burner effect. Studies of an additional appliance (burner III) confirmed that almost negligible emissions can be achieved by best technology. It is concluded that favourable constructions and combinations of burners and boilers can significantly decrease emissions from pellet burning.

The bar diagram in Fig. 2 illustrates relative proportions of assessed aromatic compounds in emissions from burner I. The first four bars of each compound demonstrate strikingly similar proportions in different chimney samples. Contrary to averages and standard deviations, the bar diagram also reveals co-variations of the proportions of some of the structurally related compounds. The fifth bar refers to a similar but larger burner appliance, but the relative proportions are still almost the same. 
Table 1 Chimney emissions ${ }^{a}$ from a free-standing pellet stove and from pellet burners in two residence boilers. Concentrations (ppm) of selected indicators of combustion performance and environmental hazards.

\begin{tabular}{lcccc}
\hline & Stove I & Burner I & \multicolumn{2}{c}{${\text { Burner } \Pi^{\mathrm{b}}}$} \\
& $7 \mathrm{~kW}$ & $25 \mathrm{~kW}$ & $20 \mathrm{~kW}$ & $10 \mathrm{~kW}$ \\
\hline Carbon dioxide & 27000 & 33000 & 62000 & 21000 \\
Carbon monoxide & 520 & 1100 & 20 & 450 \\
Methane & 7.9 & 28 & 0.5 & 4.9 \\
Benzene & 0.18 & 3.4 & 0.003 & 0.14 \\
\hline
\end{tabular}

${ }^{a}$ The chimney smoke fluxes were $50 \mathrm{~m}^{3} / \mathrm{h}$ (stove), $130 \mathrm{~m}^{3} / \mathrm{h}$ (burner I) and $240 \mathrm{~m}^{3} / \mathrm{h}$ (burner II)

${ }^{b}$ The burner is run on either high $(20 \mathrm{~kW})$ or low $(10 \mathrm{~kW})$ effect 


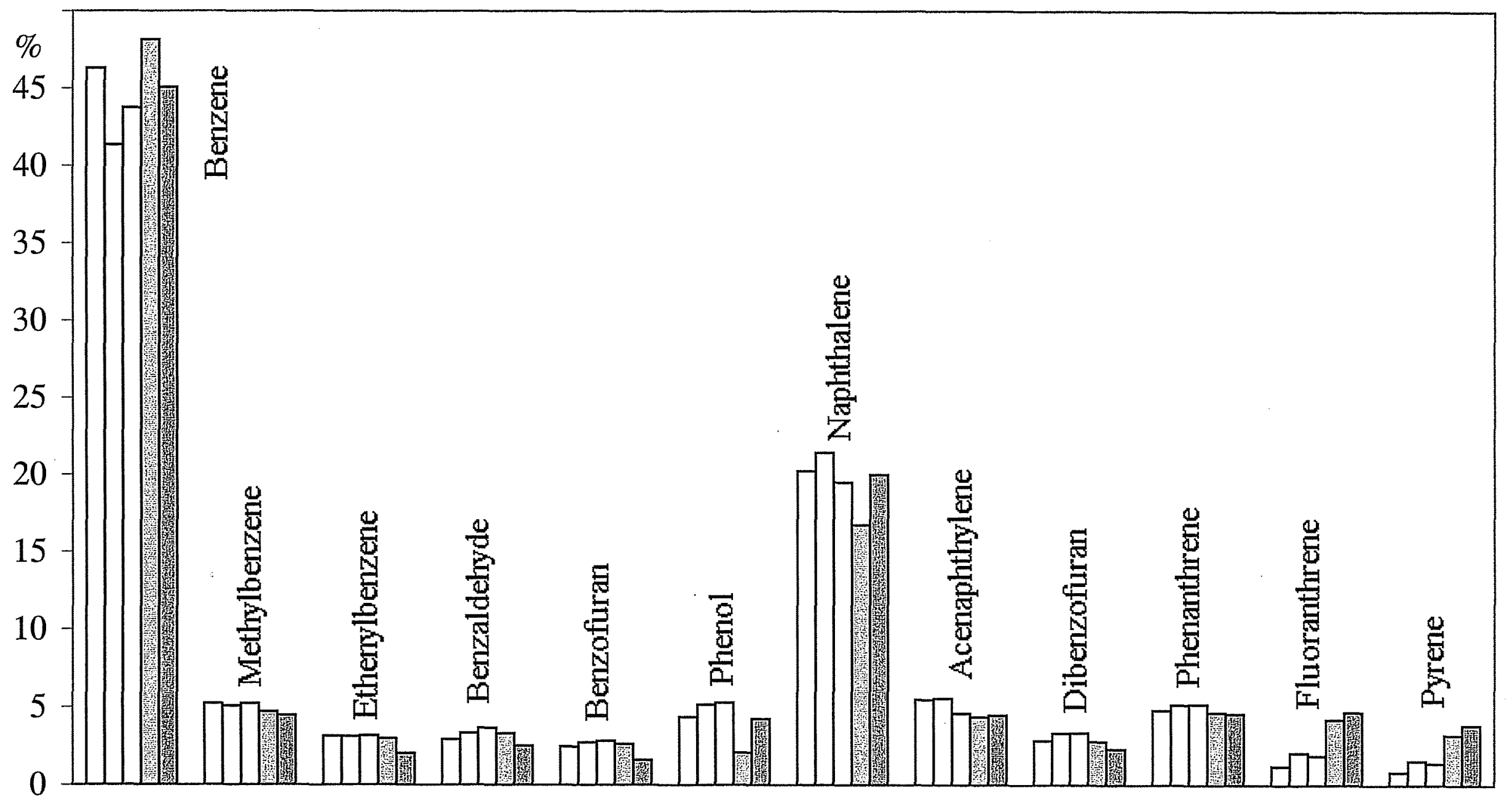

Fig. 2. Relative proportions (\%) of recorded aromatic compounds in chimney smoke from residential pellet burners. The first three samples were taken consecutively on one occasion and the fourth sample was taken weeks later from the same boiler (burner I). The fifth sample was taken from a similar appliance (burner IA). 
The major aromatic compound recorded was benzene, known as a particular health hazard because of its carcinogenicity. The concentration of benzene was about ten times higher than that of methylbenzene (toluene). A lower ratio has been assessed for firewood smoke $[6,8]$. Occurrence of ethenylbenzene (styrene) is characteristic of wood smoke $[6,8]$. The presence of oxygen-containing compounds like benzaldehyde, phenol, benzofuran and dibenzofuran was to be expected, considering the high oxygen content in wood. Naphthalene was the second most prominent compound. Phenanthrene, fluoranthene and pyrene represent polycyclic aromatic hydrocarbons $(\mathrm{PAH})$, which include many carcinogenic species. The proportions of $\mathrm{PAH}$ increase with temperature [6,9], which may explain minor differences between the samples studied. Much higher PAH proportions were observed for chimney samples from a firewood boiler [6] which also emitted methoxyphenols and 1,6anhydroglucose. These primary degradation products from lignin and cellulose were negligible from the studied boilers with pellet burners, probably as a result of a more complete combustion of the small and uniform pellets.

\subsection{Emissions from pellet stoves}

Basic emission data for a commercial pellet stove are given in Table 1, permitting comparisons with data for all reported organic compounds. The bar diagram in Fig. 3 illustrates relative proportions of assessed prominent and environmentally significant aromatic compounds. The first three bars of each compound demonstrate similar proportions for samples taken on the same occasion and more differing proportions on a second occasion. The fourth bar, representing another stove appliance, demonstrates the presence of the same prominent compounds in partly deviating proportions.

The large proportion of 2-methoxyphenols was the most remarkable difference compared to the emissions from burners. Softwood lignin gives rise to 2-methoxyphenols as primary 


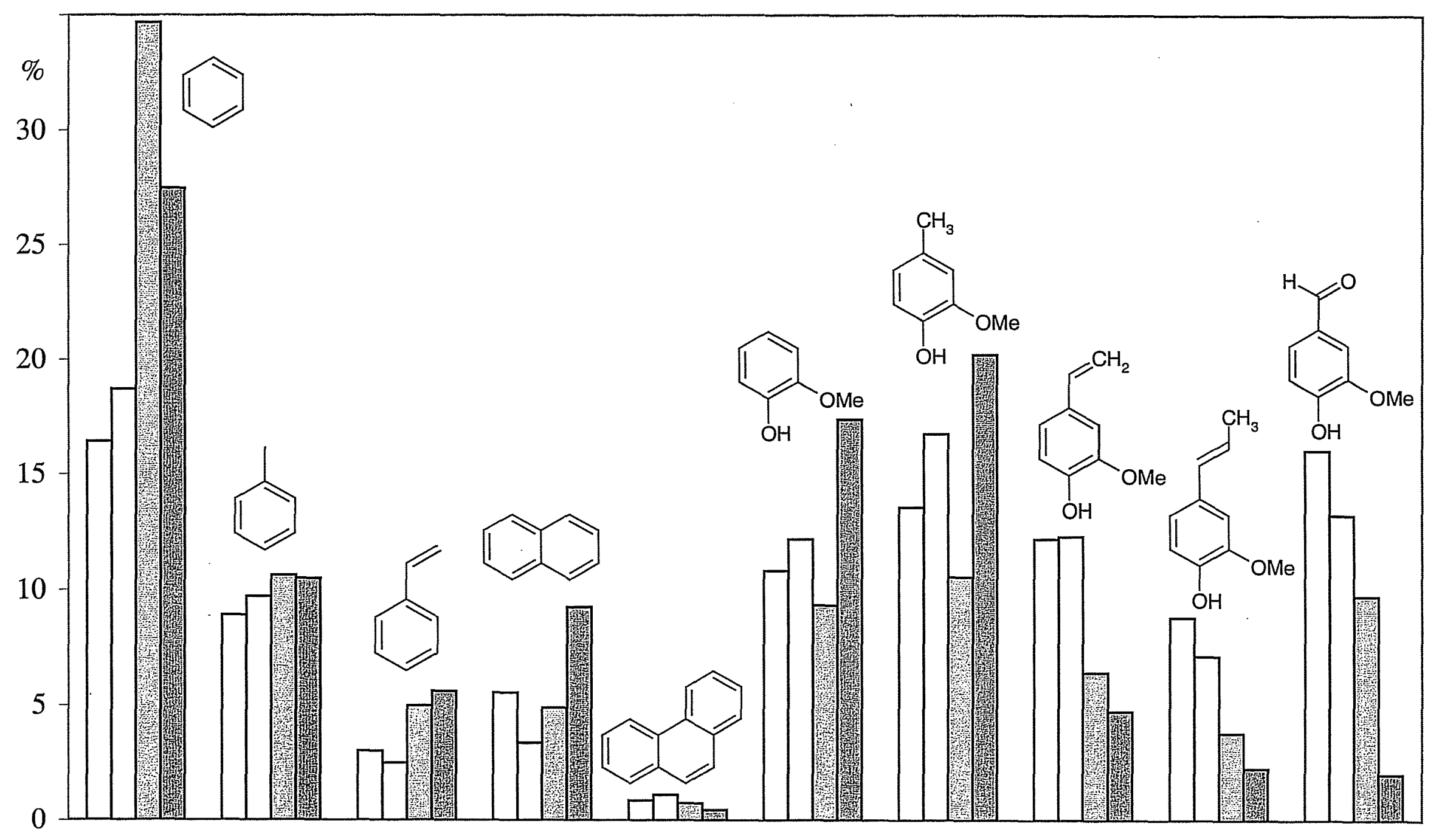

Fig. 3. Relative proportions (\%) of aromatic hydrocarbons and antioxidant methoxyphenols in smoke from wood pellet stoves. The first two chimney samples were taken consecutively, and the third sample on a later occasion from the same appliance (stove I). The fourth sample was taken in a sampling pipe from the smoke channel of a different appliance (stove II). 
thermal degradation products [9]. Their presence in smoke from stoves is probably explained by lower and less uniform combustion temperatures and by shorter gas residence times compared to the burner furnaces. The methoxyphenols are prominent components of chimney smoke from residential burning of firewood $[6,10]$.

The most prominent methoxyphenol tended to be 4-methyl-2-methoxyphenol followed by 2-methoxyphenol (guaiacol). Comparatively large proportions of 4-hydroxy-3methoxybenzaldehyde (vanillin) and the two species with unsaturated hydrocarbon sidechains were found in smoke from the most investigated stove. These three compounds were found to be the major methoxyphenols in smoke from choked burning of softwood biomass [7]. Flaming laboratory pot burning of softwood pellets gave rise to 4-methyl-2methoxyphenol and 2-methoxyphenol as major methoxyphenols [5]. The relative proportions of specific methoxyphenols may be of interest because of their varying antioxidant effect [11], which may counteract health hazards of aromatic hydrocarbons.

The relative proportions of benzene, naphthalene and polycyclic aromatic hydrocarbons were lower in the emissions from stoves than from burners. The ratio between methylbenzene and benzene was similar to that observed in emissions from firewood burning $[6,8,12]$ but significantly higher than for pellet burner emissions. The two bar graphs also illustrate more consistent compound proportions between different samples from burners than from stoves. All these observations are probably explained by specific differences in combustion conditions.

\subsection{Environmental and health aspects on emissions}

A strong environmental incentive for biofuels is that the uptake of the major greenhouse gas, carbon dioxide, by photosynthesis balances emissions from burning. This has led to a renewed interest in technologies for wood combustion [13]. The formation of methane from 
incomplete combustion should be considered because of its more than ten times stronger greenhouse effect relative to carbon dioxide. The results given in Table 1 demonstrate that the concentration of methane in smoke from pellet burning is less than $0.1 \%$ of the concentration of carbon dioxide. For firewood burning, significantly higher emissions have been observed for methane relative to both carbon dioxide and benzene [12]. It is concluded that pellet burning is favourable with respect to the greenhouse effect.

The predominance of the carcinogenic benzene in emissions from pellet burners (Fig. 2) may seem alarming with respect to health hazards. On the other hand, the concentration of benzene in the chimney pipe of the pellet burner representing best technology was very low. The benzene concentrations in rooms with tobacco smokers and inside private cars in urban traffic are actually higher [14]. The benzene emission from the pellet stove was $30 \mathrm{mg} / \mathrm{h}$ or 70 $\mathrm{g}$ during 100 days of continuous diurnal use. This is one order of magnitude lower than the yearly benzene emission from an average private car, presuming that benzene accounts for $5 \%$ of the officially reported hydrocarbon emissions from petrol-fuelled cars in Sweden. A benzene proportion of $5 \%$ relative to total non-methane hydrocarbons is typical of vehiclepolluted urban air [14]. Considering the influence of chimney height, it is also concluded that pellet burning contributes much less to human exposure to benzene than the emissions might indicate.

\subsection{Sustainable use of wood pellets and other biofuels}

Environmental and other arguments for the use of wood pellets can be properly analysed only by comparison with other biofuels. The scheme in Fig. 4 illustrates a scenario for sustainable use of wood pellets and other important biofuels originating from forest biomass.

Forest fuels are often thought of mainly as residues from forestry, remaining when timber and pulpwood have been taken out. In many regions of Sweden, branchwood is converted to 


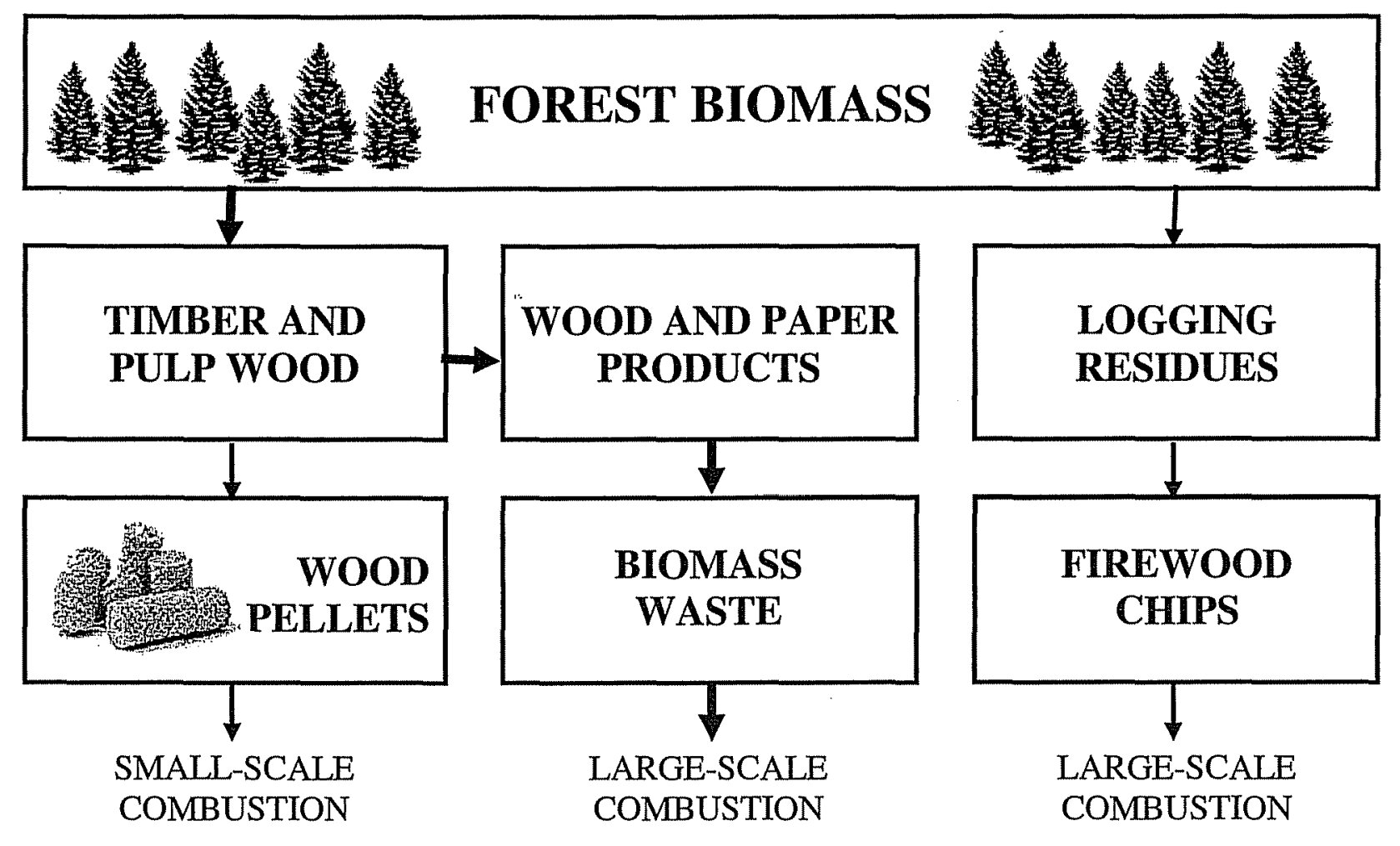

Fig. 4 Schematic illustration of the potential role of wood pellets in a system for sustainable biofuel use 
chips and used as a biofuel in heat and power plants. This means that mineral nutrients $(\mathrm{Mg}$, $\mathrm{Ca}, \mathrm{K}, \mathrm{N}, \mathrm{P}$ etc), which are mainly present in the fine parts of the trees, are removed from the forest ecosystem [15]. The removal of cations also increases soil acidification [15]. Taking out logging residues from sensitive softwood ecosystems is now questioned for these reasons. On burning, the content of mineral nutrients results in higher emissions of nitrogen oxides and larger amounts of ash. Branchwood chips are therefore suitable only for large combustion plants. Various residues from forestry may also be converted to pellets with many favourable fuel properties [16]. The objections with respect to forest ecology and emissions from residential use are however, similar to those for chips.

Waste from the wide variety of commercial products based on wood, paper and other biomass materials is a potentially very large source of biofuels. Even if the materials are recycled one or more times, they end up as waste. They are often not thought of as biofuels because they have been classified as waste and to a large extent deposited. This will change with the introduction of European directives against the deposition of organic materials. When burning is applied, a major concern is the presence of hazardous chemical additives and contaminants in the waste [17]. Large incineration plants with carefully controlled combustion conditions and advanced flue-gas purification must therefore be used.

Sawdust and wood shavings from sawmills and joinery mills may be regarded as production waste. Wood pellets made from these materials are much less contaminated than biowaste from products and are therefore better suited to small-scale burning with regard to hazardous emissions $[2,3,16]$. Residential emissions of the most toxic dioxins (PCDF/PCDD) differ dramatically between pure and waste-contaminated wood fuels [17]. The surplus of cheap biowaste also tends to make the market of wood pellets for large heating-plants unprofitable. In contrast to residues from forestry [15], neither wood pellets nor biowaste from consumer products contribute to additional losses of nutrients from the forest 
ecosystems. Sawdust and wood shavings are also favourable for small-scale burning because of a low content of mineral nutrients resulting in low emissions of sulphur and nitrogen oxides and small amounts of ashes [16].

It is concluded that wood pellets offer a favourable alternative for residential heating, whereas lower-quality biowaste fuels should be used in advanced large incineration plants. The present trend in Sweden is a rapid increase in the residential use of softwood pellets. So far, wood pellets have mainly replaced firewood, because of the convenience of the automatic pellet stoves and burners. Replacement of petroleum oil burners by pellet burners in residential boilers is now increasing particularly rapidly. The entire production of wood pellets from sawdust and planer shavings may be needed to replace residential fossil oil burning.

\section{Acknowledgement}

Generous assistance and information was given by specialists from $B a x i A B$, Äfab $A B$, Sahlins EcoTec $A B$, Nordtech Instrument $A B$, and a wide range of Swedish wood pellet suppliers and burning appliance companies. The financial support of the Swedish Energy Agency is gratefully acknowledged.

\section{References}

[1] Hillring B, Vinterbäck J. Wood pellets in the Swedish residential market. Forest Products Journal 1998, 48, 67-72.

[2] Heschel W, Rweyemamu L, Scheinbner T, Meyer B. Abatement of emissions in smallscale combustors through utilisation of blended pellet fuels. Fuel Processing Technology $1999,61,223-242$. 
[3] Vierle O, Launhardt T, Strehler A, Dumler-Grandl R, Thoma H, Schreiner M. Investigation of organic pollutants from house heating systems using biogenic fuels and correlations with other exhaust gas components. Analytica Chimica Acta 1999, 393, 131-140. [4] Lehtikangas P. Storage effects on pelletised sawdust, logging residues and bark. Biomass and Bioenergy 2000, 19, 287-293.

[5] Olsson M, Kjällstrand J and Petersson G. Oxidative pyrolysis of integral softwood pellets. Journal of Analytical and Applied Pyrolysis, in press.

[6] Kjällstrand J, Petersson G. Phenols and aromatic hydrocarbons in chimney emissions from traditional and modern residential wood burning. Environmental Technology 2001, 22, 391395.

[7] Kjällstrand J, Ramnäs O, Petersson G. Methoxyphenols from burning of Scandinavian forest plant materials. Chemosphere 2000, 44, 735-741.

[8] Barrefors G, Petersson G. Volatile hydrocarbons from domestic wood burning. Chemosphere 1995, 30, 1551-1556.

[9] Alén R, Kuoppala E, Oesch P. Formation of the main degradation compound groups from wood and its components during pyrolysis. Journal of Analytical and Applied Pyrolysis 1996, $36,137-148$.

[10] Hawthorne S B, Krieger M S, Miller D J, Mathiason M B. Collection and quantitation of methoxylated phenol tracers for atmospheric pollution from residential wood stoves. Environmental Science and Technology 1989, 23, 470-475.

[11] Kjällstrand J, Petersson G. Phenolic antioxidants in wood smoke. The Science of the Total Environment 2001, in press.

[12] Schauer J J, Kleeman M J, Cass G R, Simoneit B R T. Measurement of emissions from air pollution sources. 3. $\mathrm{C}_{1}-\mathrm{C}_{29}$ organic compounds from fireplace combustion of wood. Environmental Science and Technology 2001, 35, 1716-1728. 
[13] Strehler A. Technologies of wood combustion. Ecological Engineering 2000, 16, S25S40.

[14] Barrefors G, Petersson G. Assessment of ambient volatile hydrocarbons from tobacco smoke and from vehicle emissions. Journal of Chromatography 1993, 643, 71-76.

[15] Olsson B A, Bengtsson J, Lundkvist H. Effects of different forest harvest intensities on the pools of exchangeable cations in coniferous forest soils. Forest Ecology and Management $1996,84,135-147$.

[16] Lehtikangas P. Quality properties of pelletised sawdust, logging residues and bark. Biomass and Bioenergy 2001, 20, 351-360.

[17] Launhardt T, Strehler A, Dumler-Gradl R, Thoma H, Vierle O. PCDD/F- and PAHemission from house heating systems. Chemosphere 1998, 37, 2013-2020. 